\title{
Obesidade infantil - aspectos psicológicos envolvidos na causa e suas conseqüências
}

\author{
Cássia Maria Ramalho Salim* \\ Rute Nogueira de Morais Bicalho**
}

\begin{abstract}
RESUMO - Este estudo teve como objetivo a compreensão dos aspectos psicológicos que contribuem para a causa da obesidade infantil, e as conseqüências psicológicas. Foram selecionados 41 sujeitos na faixa etária de 6 a 16 anos, de várias classes sociais, residentes no Distrito Federal, considerados obesos pelo Índice de Massa Corporal -IMC. Entrevista semi-estruturada foi realizada com os pais e professores. Aos sujeitos foram solicitados desenhos, representando uma pessoa feia e uma bonita, e a confecção de bonecos de massa de modelar, representando por cores diferentes o que gosta nele, o que não gosta e o que é indiferente. Os resultados demonstram que os aspectos psicológicos estão presentes tanto nas causas como nas conseqüências da obesidade. As causam são: dificuldades de adaptação e ansiedade. As consequiências: não-aceitação social, isolamento e baixo nível de auto-estima. Considera-se que as condições socioafetivas são mais relevantes para fins prognósticos do que simplesmente fatores físicos.
\end{abstract}

Palavras-chave: Obesidade, infantil, aspectos psicológicos.

\section{Infantile obesity - psychological aspects involved in the cause and their consequences}

\begin{abstract}
This study had as objective the understanding of the psychological aspects that contribute to the cause of the infantile obesity, and the psychological consequences. 41 subjects were selected in the age group from 6 to 16 years, of several social classes, residents in Federal District, considered obese for the Index of Mass Corporal-IMC. Semi-structured interview was accomplished with the parents and teachers. To the subjects they were requested drawings, representing an ugly person and a beautiful one, and the making of mass puppets of modeling, acting for different colors what likes in him, what doesn't like and what is indifferent.
\end{abstract}

*Doutora em Psicologia - UnB e professora de Psicologia do Desenvolvimento do UniCEUB. Endereço eletrônico: cassiamaria@terra.com.br

*Estudante do sexto semestre de Psicologia do UniCeub. Ex. bolsista de Iniciação à Ciência. Endereço eletrônico: rutebicalho@uol.com.br

Pesquisa financiada pelo Programa de Iniciação à Ciência do UniCEUB. 
The results demonstrate that the psychological aspects are present in the causes and in the consequences of the obesity. They cause them are: adaptation difficulties and anxiety. The consequences: no social acceptance, isolation and low selfesteem level. It is considered that the partner-affectionate conditions are more relevant for prognostic ends than simply physical factors.

Key-words: obesity, infantile, psychological aspects.

A obesidade é hoje considerada uma doença crônica, multifatorial, caracterizada pelo excesso de gordura acumulado nos tecidos adiposos. Pode ser um produto da vulnerabilidade genética e de condições ambientais. É fator de risco para patologias graves, tais como diabetes, complicações cardiovasculares e hipertensão. No que se refere a complicações psicológicas, a obesidade pode causar sofrimento, depressão, dificuldades na interação social e queda na qualidade de vida. Atualmente é considerada um problema de saúde pública justificada pelo aparecimento crescente de crianças e adolescentes obesos, o que tem preocupado os profissionais e pesquisadores da área da saúde.

Conforme Fisberg (1995), a obesidade está diretamente ligada à infância, pois é nessa fase, principalmente, entre os dois e três anos, que se adquire a maior parte das células adiposas. Segundo o autor, grande parte da população obesa tem a infância como uma de suas principais vias. Sendo assim, pessoas que apresentam excesso de peso na infância tendem a ser mais obesas na vida adulta em relação àquelas que se tornaram obesas posteriormente. Além disso, os primeiros tornam-se mais propensos a desenvolver graves comprometimentos de saúde, no futuro.

Parece ser consenso que o excesso de peso na infância ocorre por uma infinidade de causas ou, como alguns autores acreditam, por uma combinação de fatores. Os mais comuns indicados na literatura incluem entre outros hábitos alimentares considerados inadequados, propensão genética, estilo de vida familiar e condição socioeconômica.

A própria vida moderna se encarrega de originar outras causas como, por exemplo, a necessidade por economia e praticidade de consumir alimentos industrializados, contendo conservantes, que a mídia se encarrega de torná-los essenciais, favorecendo substituições errôneas ou não recomendáveis à comida caseira. Além disso, alguns aspectos do desenvolvimento psicológico influenciam o consumo desmedido, constituindo-se outro fator importante. Desde pequeno se aprende que comida é "prêmio", ou ainda, para os que não querem comer, a sobremesa é a recompensa por ter consumido o que os pais querem. Por outro 
lado, ou até mesmo em conseqüência, eventos importantes da vida são sempre comemorados com comida.

Percebe-se que, nos últimos estudos encontrados sobre obesidade infantil, a literatura tem privilegiado as complicações clínicas; entretanto, a obesidade infantil e juvenil acompanha-se de transtornos que comprometem as áreas psicossociais (Ko, 2002), pois, por trás da obesidade infantil, podem estar ocorrendo distúrbios psicológicos (Morgan, Yanovski, Nguyen, et al, 2002). Conforme alguns autores, um dos sintomas mais comuns da depressão infantil pode ser a obesidade como outros transtornos alimentares (Ko, 2002).

O sofrimento emocional pode ser uma das partes mais dolorosas da obesidade, uma vez que a civilização ocidental atual enfatiza a aparência física e freqüentemente iguala atratividade com magreza. $\mathrm{O}$ fato de estar gordo ou magro na sociedade atual está intimamente ligado à imagem que a mídia vende, ou seja, sem relação ao compromisso com a saúde. A genética então é ignorada, pois o ideal é o corpo perfeito. Desta forma, pessoas com sobrepeso sentem-se sem atração. Essas considerações levam ao sentimento de baixa auto-estima, acarretando insegurança e vários outros transtornos psicológicos. Além disso, para alguém que já tem uma baixa auto-estima e tendência a sintomas de depressão, ter um "corpo imperfeito" é declarar-se preguiçoso, incapaz, relaxado e incontrolado, desencadeando dor e sofrimento (Barlow, 1999).

Segundo Mahan (1998), ironicamente os obesos são “atormentados” em uma sociedade que encoraja em demasia a alimentação. De acordo com esse autor, os mesmos aprendem respostas sociais autodefensivas e autodegradantes. Conseqüentemente, a gordura passa a ser encarada como algo "ruim", levandoos a um círculo vicioso de diminuição da auto-estima, depressão, superalimentação para o consolo, aumento de peso e rejeição social. Na atual sociedade o obeso sofre com todas suas limitações recheadas de preconceitos. As crianças sofrem muito mais que os adultos, pois ainda não sabem agir diante das críticas depreciativas.

Fricker et al. (2001) aponta que a família pode impedir o organismo da criança de aprender instintivamente a comer conforme suas necessidades. $\mathrm{O}$ alimento é oferecido a criança de forma indiscriminada. Isso ocorre porque pais ansiosos e pouco atentos à real necessidade de seus filhos não percebem que eles choram por outros motivos, e não somente quando estão com fome. Conseqüentemente, sem um aparelho psíquico maduro, a criança aprende que o alimento é a solução para todos os conflitos. Desta maneira, passa a ter dificuldades para diferenciar estados de tensão emocional, confundindo-os com a necessidade de ingerir algo. Tal associação persiste até a idade adulta, quando surgem dificuldades para o indivíduo encontrar seu estado de saciedade. Além disso, ao correr para atender a criança, os pais não permitem que elas entrem em contato com a "falta", o que, 
segundo Fisberg (1995), é uma condição imprescindível para que ela possa exercer a criatividade.

Por outro lado, para Menezes (1998), há crianças que mesmo detestando seu corpo por ser grande demais, continuam comendo em demasia porque acreditam que sendo gordas serão mais amadas ou admiradas. Muitas vezes, até certa idade, o ser "gordo" é admirado pelos pais e é considerado sinônimo de que seus filhos são "fortes" e têm "apetite de leão". Uma criança de três, quatro anos com sobrepeso é considerada pela família como "fofinha", e é este o conceito de beleza para essa idade. Contudo, quando essa criança cresce e chega à adolescência, o conceito de beleza se modifica e os quilos a mais tornam-se uma dificuldade particular, somente resolvida à custa de esforços extraordinários.

Esses dados têm relação com os dados de Pizzinatto (1992), que ressalta a existência de famílias, geralmente superprotetoras, que para negar os problemas de auto-imagem trazidos pela obesidade criam desculpas como: "ele é forte, não é gordo"; "ele já usa roupas de um homem feito". Conforme a autora, a família muitas vezes se refere a elas como sendo absolutamente normais, felizes e satisfeitas, vivendo uma infância livre de problemas, o que não corresponde à realidade dessas crianças.

\section{Critério para avaliação da obesidade}

Uma questão importante é qual o critério para se considerar uma criança obesa ou com sobrepeso. Existem vários índices utilizados como critérios (Monteiro, Victoria, Barros e Tomasi, 2000; Kosin, Kuo, Eichhonr, Leibenstein, Tulisco, 1994). Entretanto, Mahan (1998) considera que ainda não há um critério totalmente confiável, pela dificuldade de definir a obesidade. Sabe-se que a obesidade é um excesso de tecidos adiposos, mas é difícil avaliar com fidelidade a adiposidade. Para esses autores, o parâmetro deveria ter precisão na avaliação.

A Organização Mundial de Saúde (OMS) recomenda o índice de massa corporal (IMC) como um método indireto para avaliar a gordura corporal. Alguns autores, entretanto, consideram que usar somente o IMC para a avaliação de crianças não consiste em avaliação precisa, uma vez que a proporção de gordura corporal é alterada em função da idade (Fricker, 2001; Mahan, 1998; Fisberg, 1995; Pizzinatto, 1992; Lebow, 1986). Para considerar uma criança com sobrepeso, é preciso calcular o IMC, peso $(-\mathrm{Kg}) /$ altura $^{2}(\mathrm{~m})$, e transportá-lo para uma figura de peso-padrão relacionado com a idade (Fricker, 2001).

Neste estudo, para a seleção dos sujeitos foi utilizado o IMC indicado pela OMS e correlacionado com a tabela de peso-padrão para a idade. 


\section{Método}

\section{Sujeitos}

Participaram deste estudo 41 sujeitos, sendo 15 do sexo masculino ( 8 da classe média e 7 de classe baixa) e 26 do sexo feminino ( 23 de classe baixa e 3 da classe média). Todos os sujeitos foram escolhidos mediante critério da Organização Mundial da Saúde (IMC), correlacionado com a tabela de peso-padrão para a idade. Os sujeitos foram selecionados em um levantamento nas escolas públicas e particulares, consultórios endocrinológicos e de nutrição de Brasília.

\section{Procedimentos}

Para compreensão das causas e consequiências da obesidade infantil, foi realizada uma entrevista semi-estruturada com a família (representada, na maioria, pela mãe) e com o professor, para cada um dos sujeitos. As questões da entrevista para a família foram centradas nas opiniões sobre os hábitos alimentares da criança, patologias anteriores ou atuais e características psicossociais do sujeito. As questões da entrevista com o professor foram centradas sobre o comportamento do sujeito na escola, no que diz respeito ao relacionamento com seus colegas, seu desempenho escolar, atitudes na sala de aula e sobre o conhecimento de seus hábitos alimentares na escola. Cada um dos sujeitos foi entrevistado, com o objetivo de estabelecer o rapport. As questões consistiram sobre amizade, na escola e fora da escola, sobre suas brincadeiras preferidas, sobre atividades físicas e a opinião dos outros sobre elas.

As entrevistas dos familiares, dos professores e dos sujeitos foram categorizadas, com o objetivo de extrair as categorias de hábitos alimentares em casa e na escola, características psicológicas do sujeito, doenças que apresentam ou apresentaram comportamento demonstrado em casa e na escola e sobre o relacionamento do sujeito com crianças de sua faixa etária, na escola e em sua vizinhança.

A cada um dos sujeitos foi solicitado um desenho que representasse uma pessoa bonita e um que representasse uma pessoa feia. Esses desenhos foram categorizados por meio de cada traço, tamanho e forma, de acordo com a Tabela 1.

A cada um dos sujeitos foi solicitado que representasse a si mesmo, mediante um boneco de massa de modelar, utilizando três cores. $\mathrm{O}$ azul representando a parte do seu corpo da qual elas gostam, o vermelho representando a parte do corpo que elas não gostam e o amarelo a parte do corpo que lhes é indiferente. Essas características foram categorizadas, conforme Tabela 2. 


\section{Resultados}

Os resultados foram descritos em forma de Gráficos e Tabelas. Foram realizadas categorizações do relato verbal dos pais e dos professores coletados por intermédio das entrevistas semi-estruturadas. A Tabela 1 mostra o resultado por categorização dos traços dos desenhos. A Tabela 2 mostra o resultado por categorização das cores utilizadas na confecção dos bonecos.

No que diz respeito à busca para a solução da obesidade observou-se que apenas $51 \%$ das famílias tentaram tratamento nutricional para seus filhos. Foi perguntado aos pais qual seria o real motivo que os faria buscar ajuda nutricional; sem hesitação responderam que o excesso de peso é o que incomoda mais, sendo então o motivo principal. Embora a maioria tenha buscado por tratamento, 57\% dos sujeitos não aderiram ao mesmo, e apenas $43 \%$ tiveram boa adesão. Da amostra apenas 1 dos sujeitos chegou a dois anos de tratamento, o restante só permaneceu em tratamento cerca de 6 meses. Entretanto, grande parte das mães relatou que o problema de seus filhos não é nutricional e sim psicológico. Mas as dificuldades em se conseguir tratamento psicológico é um fator de desistência por parte das famílias que optam pelo tratamento nutricional como solução para a obesidade.

Das crianças que efetivamente fizeram tratamento, algumas tiveram mudanças significativas em relação ao comportamento: mais segurança, independência, iniciativa, entusiasmo, vaidade, aumento da auto-estima, menos ansiedade e menos tempo gasto em frente à TV, embora algumas mães tenham relatado que, num primeiro momento, as crianças ficam mais agressivas, nervosas e ansiosas, por não poderem comer mais o que querem, passando a ter horários regulares para as alimentações e não mais a todo instante. A ansiedade também é encontrada nos sujeitos quando está próxima a visita ao nutricionista que, segundo as mães, se sentem mais ansiosas e com medo de não terem alcançado a meta proposta para o emagrecimento.

Foi observado que a incidência de obesidade na família é maior nas mulheres (tias, avós, mães) maternas e paternas do que nos homens de ambas as famílias. Na maioria da amostra, pelo menos um dos pais tem o peso acima do ideal. Além disso, muitos pais que hoje estão com peso estabilizado já tiveram sobrepeso em algum momento da vida, geralmente na adolescência.

A obesidade acaba dificultando os relacionamentos interpessoais dos sujeitos, embora os pais afirmem que $64 \%$ dos sujeitos têm muitos amigos e $36 \%$ têm poucos amigos. Contudo, este dado não corrobora com os relatos dos professores pois, segundo estes, $60 \%$ dos sujeitos não têm muitos amigos, contra $40 \%$ que apontam uma boa interação com os colegas. A posição dos sujeitos é semelhante a dos professores, visto que $68 \%$ deles relataram sentirem dificuldades de se relacionar com colegas da escola, justamente pelo fato destes colocarem apelidos nos sujeitos. 
Embora a obesidade dificulte as atividades esportistas, os sujeitos relataram que suas atividades preferidas envolvem corridas, tais como: pique-pega, queimada, vôlei e futebol. São atividades realizadas sem compromisso para emagrecer, pois somente $29 \%$ dos sujeitos praticam atividades físicas efetivamente com o objetivo principal de reduzir medidas. Além deste fato, outro que influencia na obesidade é o tempo gasto em frente à TV. Quase toda a amostra (95\%) passa bastante tempo assistindo à televisão, sendo que $70 \%$ destes se alimentam diante da TV.

O comportamento dos pais é fundamental para o desenvolvimento da obesidade. Neste sentido, os dados indicam que os pais são passivos, ou seja, os filhos fazem o que querem, principalmente em relação à alimentação. Por outro lado, algumas famílias relataram que o diálogo é fundamental. Outro comportamento significativo é a preocupação e culpa da mãe, mais do que o pai, no que diz respeito ao excesso de peso do filho. Segundo elas, por algum motivo fizeram ou deixaram de fazer algo que prejudicasse o filho neste sentido.

As críticas aos obesos são inevitáveis. As mães relataram que os sujeitos participantes recebem muitas críticas (apelidos depreciativos), vindas da escola e da família. Os sujeitos relatam que as críticas vêm mais dos colegas da escola. Conforme a Figura 1, as reações dos sujeitos às críticas, segundo as mães, são de muita tristeza, choro e isolamento; além disso, muitos revidam com agressão verbal e física. Esse tipo de reação também é encontrado nos relatos dos sujeitos e dos professores. Outro dado encontrado é que quando o sujeito recebe as críticas, fica nervoso e ansioso, como conseqüência, come em demasia.

As constantes críticas contribuem para que esses sujeitos diminuam mais ainda a sua auto-estima. Pais e professores acham que os sujeitos têm baixa autoestima: $48 \%$ dos nais dizem aue a auto-estima dos suieitos é haixa e $39 \%$ dos

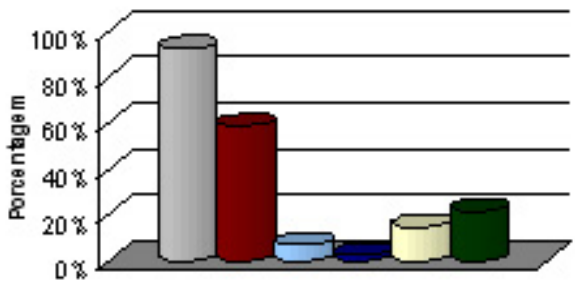

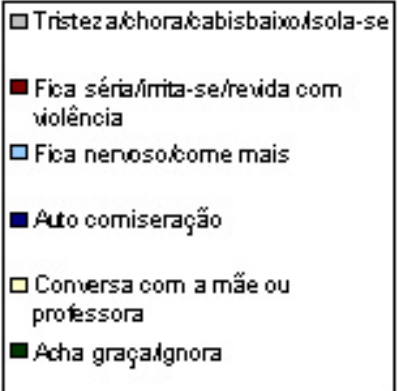

Figura 1 - Reação às críticas, segundo os pais. 
professores acham o mesmo. No momento em que recebem tais críticas, pais e professores relatam que os sujeitos se sentem inferiores aos demais e percebem um certo isolamento.

No que se refere à causa da obesidade dos sujeitos, os pais relataram que os hábitos alimentares considerados inadequados foram fundamentais para o excesso de peso de seus filhos. As mudanças familiares, tais como nascimento de um irmão, separação dos pais, mudança de cidade ou estado, perda de um ente, mudança de escola, ausência de um dos pais, dificuldades financeiras e adoção foram fatores determinantes para a causa da obesidade. Os pais notaram que, após um desses fatos ou a combinação com outros, os sujeitos começaram a adquirir peso em demasia. Algumas drogas, como cortisol, vitaminas e soro fisiológico foram citadas por alguns pais que asseguram serem a causa da obesidade. A hereditariedade foi citada por apenas quatro famílias como sendo a causa principal. Várias famílias não citaram apenas uma, mas duas ou mais causas para a obesidade, ou seja, a combinação de alguns desses fatores concomitantes. De toda a amostra, apenas $24 \%$ sujeitos nasceram acima do peso e permanecem assim até o fechamento desta pesquisa. Os outros $76 \%$ adquiriram peso durante o desenvolvimento por alguma causa ou várias das causas acima citadas.

Conforme Figura 2, os professores citaram vários comportamentos concomitantes num mesmo indivíduo; um sujeito, por exemplo, pode ser interessado, agressivo e tímido. Apesar de ser interessado nos estudos, grande parte da amostra é classificada pelos professores como tendo um desempenho regular. Certos comportamentos, tais como agressividade, preguiça e inquietude foram verificados com mais frequiência em alguns momentos ou períodos como resposta a um problema familiar, por exemplo, perda de um ente, nascimento de um irmão e outros.

De acordo com os professores, a procedência do lanche escolar dos sujeitos na grande maioria é de casa; geralmente são bolos, pipocas, sucos, refrigerantes, sanduíches e outros; $24 \%$ dos sujeitos compram na escola e $12 \%$ dos sujeitos
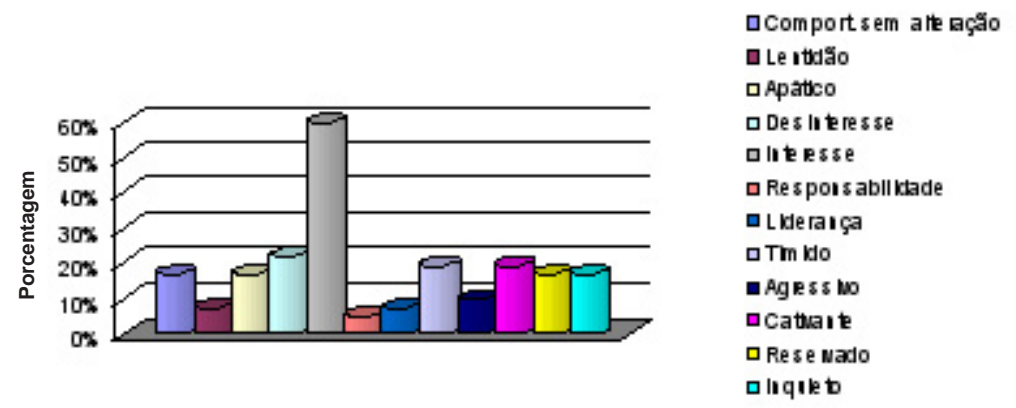

Figura 2 - Comportamentos dos sujeitos em sala de aula. 
lancham o que a escola oferece, freqüentemente, comida. O tipo de alimentação comprado na escola é supercalórico e rico em gorduras (salgados, refrigerante, doces...). Apenas 5\% compram um lanche à base de frutas e com baixo teor de gordura.

No que diz respeito ao comportamento das crianças obesas, os pais relataram que são ansiosas, bem como agressivas. Parece que a obesidade, no entanto, não prejudica a espontaneidade da criança, pois a metade dos sujeitos foram considerados pelos familiares e professores como extrovertidos. Uma outra característica bastante relatada sobre a criança obesa é a de ser carinhosa.

Em relação aos desenhos dos sujeitos, representando uma pessoa bonita e uma feia estão categorizados e as categorias e subcategorias foram descritas na Tabela 1.

De acordo com a Tabela 1 e Figura 3, os resultados indicam que a pessoa bonita é representada pela pessoa magra e a pessoa feia é representada pelo excesso de peso. Tal representação ocorre a partir dos 12 anos nos meninos e a partir dos 8 anos nas meninas. Das 26 meninas, apenas 3 estão abaixo dos 8 anos. Dos 15 meninos, apenas 6 estão abaixo dos 12 anos. Dos desenhos que não representaram tais diferenças corporais, 7 meninas tinham idade acima dos 8 anos e apenas 1 menino acima de 12 anos. Alguns sujeitos representaram o inverso, isto é, representaram a pessoa feia como magra e a pessoa bonita como gorda.

No que diz respeito ao sexo dos desenhos, 7 meninos desenharam ambas as pessoas, bonita e feia, do sexo masculino e 1 desenhou do sexo feminino. Já as

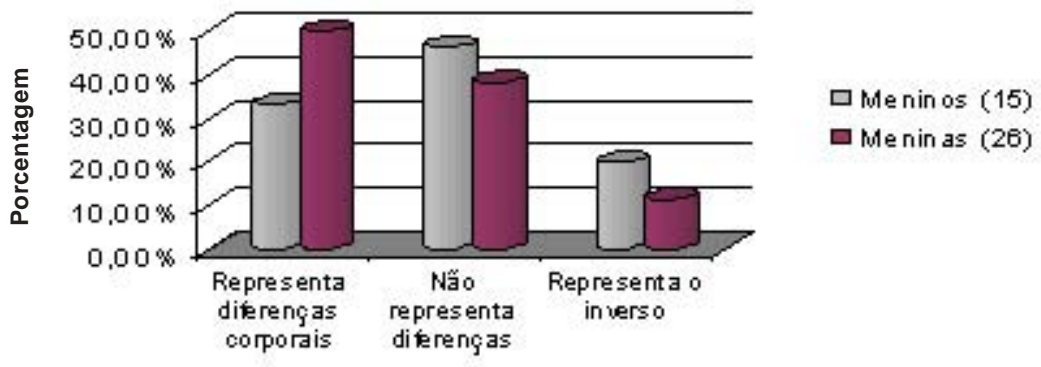

Figura 3 - Diferenças pessoais nas representações da pessoa bonita e feia. 
Tabela 1. Categorização dos desenhos.

\begin{tabular}{|c|c|c|c|}
\hline \multirow{2}{*}{ Cabelos } & Bonito & $\begin{array}{l}\text { Representação de cabelos lisos } \\
\text { Representação de cabelos compridos } \\
\text { Representação de cabelos ondulados } \\
\text { Representação de cabelos na cor preta } \\
\text { Representação de cabelos na cor amarela }\end{array}$ & $\begin{array}{l}13 \\
1 \\
6 \\
2 \\
2\end{array}$ \\
\hline & Feio & $\begin{array}{l}\text { Sem representação do cabelo } \\
\text { Representação de cabelos lisos } \\
\text { Representação de cabelos curtos } \\
\text { Representação de cabelos encaracolados } \\
\text { Representação de cabelos despenteados } \\
\text { Representação de cabelos na cor amarela } \\
\text { Representação de cabelos na cor preta } \\
\text { Representação de cabelos volumosos }\end{array}$ & $\begin{array}{l}4 \\
1 \\
3 \\
3 \\
10 \\
3 \\
2 \\
1\end{array}$ \\
\hline \multirow[t]{2}{*}{ Rosto } & Bonito & $\begin{array}{l}\text { Com formato do pescoço } \\
\text { Sem formato de pescoço }\end{array}$ & $\begin{array}{l}2 \\
1\end{array}$ \\
\hline & Feio & $\begin{array}{l}\text { Com formato de pescoço } \\
\text { Sem o formato do pescoço } \\
\text { Presença de marcas na pele (espinhas) }\end{array}$ & $\begin{array}{l}1 \\
2 \\
2\end{array}$ \\
\hline \multirow[t]{2}{*}{ Tronco } & Bonito & $\begin{array}{l}\text { Representação do tronco } 1,5 \text { vez menor em relação ao outro } \\
\text { desenho } \\
\text { Representação do tronco entre } 2 \text { a } 6 \text { vezes menor que o outro } \\
\text { desenho } \\
\text { Representação da cintura } \\
\text { Representação dos quadris }\end{array}$ & $\begin{array}{l}12 \\
13 \\
5 \\
3\end{array}$ \\
\hline & Feio & $\begin{array}{l}\text { Representação do tronco } 1,5 \text { vez maior em relação ao outro } \\
\text { desenho } \\
\text { Representação do tronco entre } 2 \text { a } 6 \text { vezes maior que o do } \\
\text { outro desenho } \\
\text { Representação da cintura } \\
\text { Representação dos quadris } \\
\text { Não há representação da cintura } \\
\text { Não representação dos quadris } \\
\text { Representação da barriga }\end{array}$ & $\begin{array}{l}12 \\
13 \\
0 \\
0 \\
5 \\
5 \\
3\end{array}$ \\
\hline \multirow[t]{2}{*}{ Boca } & Bonito & Representação através de semi curva inclinada para cima & \\
\hline & Feio & $\begin{array}{l}\text { Representação da boca através de rabiscos } \\
\text { Representação da boca com dentes separados } \\
\text { Representação da boca com aparelho nos dentes } \\
\text { Representação por um traço reto horizontal }\end{array}$ & $\begin{array}{l}1 \\
1 \\
1 \\
3\end{array}$ \\
\hline Pernas & Bonito & $\begin{array}{l}\text { Representação das pernas com largura menor que o outro } \\
\text { desenho }\end{array}$ & \\
\hline \multirow{3}{*}{ Olhos } & Feio & $\begin{array}{l}\text { Representação das pernas com largura maior que o outro } \\
\text { desenho }\end{array}$ & \\
\hline & Bonito & Sem a representação de óculos & $* *$ \\
\hline & Feio & Com a representação de óculos & $* *$ \\
\hline
\end{tabular}


meninas, 16 delas representaram ambos os desenhos do sexo feminino. Quando o sexo é diferente, ocorreu um fato interessante: 6 meninos e 10 meninas representaram as pessoas bonitas do sexo feminino e as pessoas feias do sexo masculino, ou seja, para ambos os sujeitos, sempre a pessoa bonita é do sexo feminino e a pessoa feia do sexo masculino. Em um dos desenhos o sexo não foi identificado.

Em relação aos bonecos feitos com massa de modelar, os quais deveriam expressar as partes do corpo de que gostam, as que não gostam e as partes que lhes são indiferentes, foram categorizados e as categorias mais gosta, menos gosta e é indiferente foram descritas na Tabela 2 e representadas na Figura 4.

Na Figura 4, o gráfico mostra que 68\% dos sujeitos não gostam de seu tronco,

Tabela 2. Categorização dos bonecos.

\begin{tabular}{lcllll}
\hline \multicolumn{1}{c}{ Menos gosta } & $\mathbf{N}^{\mathbf{0}}$ & \multicolumn{1}{c}{ Mais gosta } & $\mathbf{N}^{\mathbf{0}}$ & Indiferente & $\mathbf{N}^{\mathbf{0}}$ \\
\hline Cabeça & 02 & Cabeça & 27 & Cabeça & 09 \\
Tronco & 28 & Tronco & 09 & Tronco & 04 \\
Membros inferiores & 07 & Membros inferiores & 18 & Membros inferiores & 15 \\
Membros superiores & 07 & Membros superiores & 26 & Membros superiores & 07 \\
Cabelos & 05 & Cabelos & 10 & Cabelos & 04 \\
Nariz & 03 & Seios & 01 & Mãos & 01 \\
Espinhas no rosto & 02 & Olhos & 08 & Boca & 05 \\
Barriga & 02 & Nariz & 06 & Nariz & 04 \\
Olhos & 01 & Boca & 05 & Olhos & 02 \\
Pés & 01 & Pescoço & 01 & Pés & 01 \\
& & Pés & 01 & Pescoço & 02 \\
\hline
\end{tabular}

\section{口CABEÇA}

-TRONCO

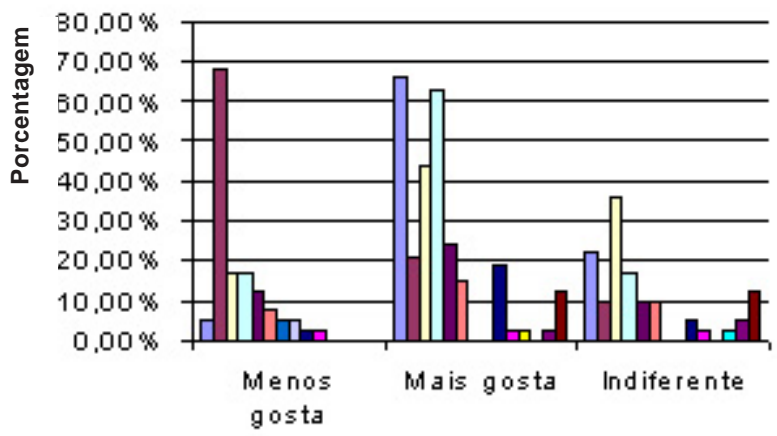

口ME MBROS INFERIORES

口ME MBROS SUPERIORES

DCABELOS

口NARE

口ESPIN HAS NO ROSTO

口BARRIGA

-OLHOS

口P ES

口SEDS

M⿵̃os

-P ESCOÇO

- BOCA

Figura 4 - Categoria extraídas dos bonecos em massa de modelar. 
sendo que pelo menos 2 dos sujeitos mencionam especificamente a barriga. Foram mencionados espinhas no rosto como algo não desejado. A parte escolhida como preferida por $66 \%$ dos sujeitos é a cabeça e a segunda preferência relatada consiste nos membros superiores (63\%). Estes resultados sugerem que os sujeitos da amostra podem ter baixo nível de auto-estima, uma vez que muitos demonstram descontentamento com a parte mais representativa do corpo, que é o tronco.

\section{Discussão}

Tendo como base as análises dos procedimentos, os resultados demonstram que existem causas psicológicas na obesidade infantil, bem como aspectos psicológicos que estão presentes como consequiência da mesma. Encontrou-se uma correspondência com os estudos de Pizzinato (1992) e Fisberg (1995), que estes afirmam ser a obesidade infantil uma doença de consequiências graves que se instala em múltiplos órgãos, acarretando inúmeros prejuízos, tanto físicos como psíquicos. Além de trazer sérios riscos para a pessoa, a obesidade é atualmente um dos mais graves problemas de saúde pública do mundo.

Neste estudo, foi observado que as condições socioafetivas da criança acarretam comportamentos que se tornam mais relevantes para fins prognósticos do que os fatores físicos, pois nenhum caso de obesidade desta amostra, aparentemente, tem como causa primária distúrbios glandulares, endócrinos ou hipotalâmicos. O que foi relatado nas entrevistas com a família, parece que, na grande maioria, a causa advém de comprometimentos emocionais, tais como: dificuldade de se adaptarem às dinâmicas familiares (nascimento de um irmão, separação dos pais, mudança de estado ou cidade) e a ansiedade. E fatores ambientais e sociais, como a alimentação desregrada e o sedentarismo.

Em relação a tais dificuldades socioafetivas parece-nos que a ansiedade é uma causa importante, pois ela é descrita em boa parte da amostra e, sem dúvida, seu controle é de fundamental relevância para um bom resultado nutricional e psicológico. No que diz respeito à dinâmica familiar foram encontrados muitos sujeitos de classe baixa, com dificuldades financeiras, pais separados, ciúmes ao nascimento dos irmãos, além do que, muitas das famílias desta amostra relatam inúmeras experiências de vida, que apresentam conflitos familiares, sociais e afetivos, que são citados como fatores desencadeantes da obesidade ou do sobrepeso da criança. Este resultado corrobora com os achados de Fricker et al (2001); Fisberg (1995); Pizzinatto (1992) e Senise (1970). Alguns dos sujeitos desta pesquisa parecem ter como causa da obesidade a combinação de vários fatores: genéticos, nutricionais, inatividade física e, em poucos sujeitos, uso de drogas, tais como cortisol, vitaminas 
e soros fisiológicos.

Quando um dos pais é obeso, a criança tem $40 \%$ de chances de se tornar obesa. Quando os dois pais são obesos, essa chance sobe para $80 \%$. Mas, segundo Stunkard (1991) (citado em Costa \& Biaggio, 1998), a hereditariedade tem sido vista de modo crescente como a maior determinante da obesidade humana, sendo que esta requer um meio ambiente propício para se manifestar, ou seja, a genética fornece ao indivíduo a predisposição à obesidade, porém é o ambiente que vai agir suprimindo ou expressando tal predisposição (Mahan, 1998).

Ao considerar o fator genético nesta pesquisa, foi visto que alguns sujeitos obesos ou com sobrepeso tinham pelo menos um dos pais, com obesidade ou sobrepeso. Outros pais relataram que já tiveram problemas com a balança em algum momento, geralmente na adolescência. $\mathrm{O}$ fator nutricional mais mencionado foi que as escolhas e preferências na alimentação são carboidratos, compostos de gordura e glicose. As principais causas relatadas nas entrevistas foram a inatividade física e a superalimentação. No que diz respeito à inatividade física, os relatos confirmam que o sedentarismo se faz presente em grande parte da amostra, sendo poucas as crianças que fazem exercícios efetivos. A superalimentação foi constatada por meio de relatos sobre o que os sujeitos comem com o consentimento ou pelo estímulo dos pais.

Conforme os estudos de Fricker et al (2001); Fisberg (1995); Pizzinatto (1992), os erros alimentares impostos ou permitidos aos sujeitos estão intimamente relacionados aos hábitos e comportamento dos adultos. Muitas mães são ansiosas e com isso podem fazer seu filho engordar demais simplesmente por pensar que $o$ peso dele está abaixo do esperado. A questão dos limites também influencia no sobrepeso dos sujeitos, pois os pais têm dificuldade para impor disciplina aos filhos, deixando-os fazer o que querem e quando bem quer. Como encontrado nesta pesquisa, o pai impõe com mais eficiência os limites, entretanto, muitos pais não se preocupam tanto e nem se sentem culpados pelo sobrepeso do filho, tanto quanto a mãe. Sendo assim, o pai impõe limites para outras questões e acaba sendo passivo em relação ao sobrepeso. Por outro lado, muitas famílias não admitem que alimentam mal seus filhos ou que são incapazes de impor disciplina.

Além deste fato e do sedentarismo já citado, quase todas as crianças desta amostra passam horas assistindo à televisão e, na maioria das vezes, petiscam enquanto assistem. Além da televisão contribuir para aumentar o risco de obesidade por desviar a criança das atividades físicas, induz à ingestão de alimentos altamente calóricos, visto que o número de comerciais que anunciam doces, balas, chocolates e outros alimentos de conteúdo energético são inúmeros (Varella, 2002).

As conseqüências da obesidade são inúmeras: diabetes, hipertensão, elevação 
dos níveis de colesterol e triglicérides, maior produção de insulina, distúrbios cardiovasculares, alterações ortopédicas, dermatológicas e respiratórias, problemas psicossociais, não-aceitação social com conseqüente isolamento social, e baixo nível de auto-estima. Na maioria da amostra os sujeitos não estão satisfeitos com seus corpos, portanto, supõe-se baixa auto-estima como consequiência do sobrepeso.

Em geral a família do sujeito é obesa ou já possui antecedentes familiares obesos o que contribui para um outro padrão e a criança é mais bem aceita. Quando isso não ocorre, ou seja, ela não é bem aceita pela família, além de ser hostilizada dentro de casa, o é também fora dela, continua tendo de conviver com o preconceito. Como visto nos resultados, as maiores críticas vêm dos amigos e, em segundo lugar, dos próprios parentes, mas as críticas dos colegas possuem um peso maior do que as vindas da família. Entretanto, as críticas que sofrem as crianças e os obesos em geral não partem apenas da família e dos colegas, mas também da sociedade e da mídia. E a reação das crianças diante dessas críticas é de tristeza e agressões, tanto físicas como verbais. Ao agir dessa forma a criança é hostilizada mais ainda e, conseqüentemente, pode afastar-se do convívio social e das atividades esportistas, agravando enormemente o processo.

As famílias acreditam que o ser gordo pode também significar falta de controle de impulsos, preguiça, desleixo e relacionam com baixos níveis de auto-estima. A transmissão desses conceitos, até mesmo por parte da família, é um fator de sofrimento para os sujeitos. Além disso, as famílias consideram que a gordura é sinônimo de feiúra, mas até certa idade o ser gordo é admirado pela família. Portanto, de acordo com os desenhos do sujeitos, o conceito de beleza é inexistente para as meninas abaixo dos nove e oito anos e para os meninos, abaixo dos doze anos. Os meninos não se incomodam tanto no que diz respeito ao conceito de beleza predominante na cultura e seus desenhos não retratam a obesidade da mesma forma que as meninas.

Ainda de acordo com o conceito de beleza, os relatos nos indicam que as famílias só buscaram tratamento nutricional porque seus filhos estavam bem acima do peso, isto é, a primeira visão que se tem da obesidade é a feiúra (externo) e não as complicações de saúde dela decorrentes (interno). As famílias verificaram que esses quilos a mais estavam prejudicando a criança em algum momento, principalmente, em relação à auto-estima e à interação. Entretanto, dos poucos sujeitos que foram inseridos num tratamento nutricional, menos ainda aderiram ao mesmo. Verifica-se que as pessoas são programadas para absorver calorias adicionais e armazená-las em forma de gordura. O que podemos concluir, que corresponde com outros estudos, é que no mundo de hoje, em que todos estão cercados por alimentos supercalóricos, essa qualidade de proteger o organismo de situações inesperadas torna-se um desafio. A prevenção à obesidade é de extrema relevância para o desenvolvimento da criança. Deixá-la chegar à vida adulta com 
excesso de gordura no corpo, além de aumentar o risco de várias doenças, é começar uma luta sem fim contra a balança (Varella, 2002). A perspectiva principal é a busca de saúde e qualidade de vida, mais do que o corpo perfeito.

O objetivo deste estudo foi o de verificar as causas e conseqüências psicológicas da obesidade. Alcançamos nosso objetivo quando nos foi mostrado que a ansiedade e tristeza são características relacionadas à obesidade, fato relatado tanto pelos pais como pelos professores. Entretanto, em estudos futuros, estes relatos devem ser confirmados pela aplicação de escalas de ansiedade e de depressão nos sujeitos, para a verificação da genuinidade de tais relatos.

\section{Referências}

BARLOW, D. I. (1999). Manual Clínico dos Transtornos Psicológicos. (Osório, M. R. B., Trad.) Porto Alegre: Ed. Artmed.

COSTA, J., M., A. \& BIAGGIO, A., M., B. (1998). Aspectos Emocionais da Obesidade: Ansiedade e Raiva. Arquivos Brasileiros de Psicologia. Vol. 50, n 3, p.30 a 33.

FISBERG, M. (1995). Obesidade na Infância e na Adolescência. São Paulo: Fundação BYK.

FRICKER, J. et al. (2001). Guia da Alimentação das Crianças da Concepção à Adolescência. Coleção: Medicina e Saúde. Instituto Piaget.

KO, M. (2002). A Spreading Crisis. Report NewsMagazine. 4/1/2002, Vol 29 Issue 7, p34

KRAUSE, M.V \& MAHAN, L. K. (1998). Alimentos, Nutrição e Dietaterapia. (Food, nutrition and dietterapy) Trad. André Luís Montagnini et alii, $9^{a}$ edição, São Paulo: Livraria Roca.

LEBOW, M. D. (1992). Obesidad Infantil: Una nueva frontera de la terapia conductal. Buenos Aires: Paidos.

MENEZES, O. A. (1998). Obesidade: Motivações Inconscientes. São Paulo: Paulus.

MONTEIRO, P. O. A. VICTORA, C. G.; BARROS, F. C.; TAMASI,E. (2000). Diagnóstico de Sobrepeso em Adolescentes: Estudo de Desempenho de Diferentes Critérios para o Índice de Massa Corporal. Revista Saúde Pública. 34(5): 506-13, out. 2000.

MORGAN, C.M.; YANOVSKI,S.Z.; NGUYEN,T.T.; MCDUFFIE. J.; SEBRING, N. G.; JORGE, M. R. KEIL, M. YANOVSKI, J. A. (2002) Loss of Control Over Eating, Adiposity, and Psychopathology in Overweight Children. International Journal of Eating Disorders. May Vol. 31 Issue 4, p430 -442.

PIZZINATTO, V. T. (1992). Obesidade Infantil: processo psicossomático evolutivo. São Paulo: Sarvier.

SENISE. N. (1970). Pare de engordar: obesidade um problema psicológico. $2^{\circ}$ ed. Rio de Janeiro: Record.

VARELLA, D. (2002). Crianças obesas e sedentárias. Folha de São Paulo. E.16, 21 de setembro. 


\section{$3^{\circ}$. Congresso UniCEUB de Ciências da Saúde}

04 a 08 de Outubro de 2004

Inscreva-se pela Internet no site www.uniceub.br

Participe! 